\title{
Use of GIS-Derived Landscape-Scale Habitat Features to Explain Spatial Patterns of Fish Density in Michigan Rivers
}

\author{
Sara M. CReque*1 AND Edward S. Rutherford \\ Institute for Fisheries Research, School of Natural Resources and Environment, \\ University of Michigan, 218 Museums Annex Building, \\ 1109 North University Avenue, Ann Arbor, Michigan 48109, USA
}

\section{Troy G. ZORN}

Michigan Department of Natural Resources, Fisheries Division, Marquette Fisheries Research Station, 484 Cherry Creek Road, Marquette, Michigan 49855, USA

\begin{abstract}
Both site- and landscape-scale processes play important roles in the biological communities of rivers. Understanding the influences of these processes on fish abundance can help direct management and research efforts toward appropriate habitat variables and scales. We used multiple linear regression analysis of a regional fish and habitat database to determine the feasibility of using geographical information systems (GIS)-derived landscape-scale habitat variables to explain the spatial variation in the density of five sport fish species (Chinook salmon Oncorhynchus tshawytscha, steelhead O. mykiss, brown trout Salmo trutta, brook trout Salvelinus fontinalis, and white sucker Catostomus commersonii) in the rivers of Michigan's Lower Peninsula. We compared these models with those developed using site-scale variables traditionally measured in the field. Landscape-scale riverine habitat variables obtained through GIS analysis and modeling of catchment characteristics accounted for $18-69 \%$ of the variation in fish density. Landscape estimates of mean July water temperature were negatively correlated with the density of brook trout, brown trout, and Chinook salmon. Drainage area was negatively correlated with the density of steelhead and white suckers, and $90 \%$ exceedence flow yield (a measure of flow stability) was positively correlated with the density of Chinook salmon and steelhead. Site-scale habitat variables explained less $(12-57 \%)$ of the variation in fish density than landscape-scale variables. In the site-scale models, depth was negatively related to all species' densities, and the percentage of soft substrates was positively correlated only with white suckers. Although there was still much unexplained variation in density, our models provide insight into key habitat variables that influence fish density patterns on a large scale.
\end{abstract}

Physical habitat has a strong influence on the spatial patterns in the distribution and abundance of fishes and aquatic insects. Physical habitat conditions in aquatic systems determine the distributions of organisms and availability of food and can mediate predation and competition among fishes (Frissell et al. 1986; Schlosser and Kallemeyn 2000). In rivers, physical habitat can be measured at several spatial scales. This hierarchy of habitat scales is important to population and community dynamics (Maxwell et al. 1995; Schlosser 1995; Schlosser and Kallemeyn 2000). Determining which habitat variables and spatial scales have the most influence on fish communities is key to

\footnotetext{
* Corresponding author: screque@uiuc.edu

${ }^{1}$ Present address: Illinois Natural History Survey, Lake Michigan Biological Station, 400 17th Street, Zion, Illinois 60099, USA.
}

Received July 23, 2004; accepted July 28, 2005

Published online October 26, 2005 effective and efficient management. Models describing the relationships between habitat and fish density at the appropriate spatial scale are needed to help develop conservation and restoration plans for streams, especially in areas with high anthropogenic influences.

Local or site-specific habitats and processes historically have been considered the primary factors that regulate fish populations in trout streams (Wiley et al. 1997). Site-scale physical habitat characteristics and mechanisms that regulate where fish occur and reproduce include temperature, substrate, available cover, velocity, vegetation, competition and predation, and fishing pressure (Gordan and MacCrimmon 1982; Fausch et al. 1988; Pusey et al. 2000). While these habitat features may regulate populations of algae, macroinvertebrates, and fish (Wiley et al. 1997), site-specific studies often are conducted under a limited range of environmental conditions, and their results may be difficult to apply to broader regions, which often have more environmental variability and are 
of concern for management (Fausch et al. 1988; Bryce and Clarke 1996; Pusey et al. 2000). For example, the site-scale habitat variables important for predicting fish densities and distributions in Michigan's Upper Peninsula did not predict those densities and distributions well in the state's Lower Peninsula (Wang et al. 2002, 2003).

Landscape-scale processes largely determine the environmental setting of streams and play an important role in their biological communities. Because many important aspects of stream habitat are influenced by the characteristics (e.g., land use, geology, soil, and climate) of the surrounding catchment (Frissell et al. 1986; Larsen et al. 1986; Wiley et al. 1997), landscape-scale variables can explain patterns of fish distribution and abundance without habitat information at the local scale (Hughes et al. 1987; Lyons 1996; Wiley et al. 1997; Zorn et al. 2002). Catchment landscapes determine the extent, timing, and route of water, sediment, and nutrient transport to local sites, and the nature of this transport defines many ecological characteristics of a site (Richards et al. 1996; Allan et al. 1997; Seelbach and Wiley 1997). For example, hydrologic regimes vary substantially throughout the Lower Peninsula of Michigan because of varied glacial geology; some streams are primarily runoff driven, while others are primarily groundwater driven. Ninety percent exceedence flow (the discharge that is exceeded $90 \%$ of the time within a year), when standardized by drainage area to give the $90 \%$ exceedence flow yield (LFY; also called low-flow yield), is an excellent indicator of a river's flow stability and groundwater input (Zorn et al. 2002). Higher LFYs indicate higher contributions of groundwater and, in Michigan, more stable flows throughout the year.

Many site-scale variables can be indexed by relatively few landscape variables. For example, Midwestern stream communities appear to be affected by the combination of a few, large-scale hydrogeological factors (Wiley et al. 1997; Zorn et al. 2002). In Michigan, patterns of fish species assemblage have been predicted using only drainage area and LFY. Distinct peaks in the abundance of each species occur under particular combinations of LFY and drainage area (Zorn et al. 2002). In Idaho streams, predictable relationships were evident between the number of fish species and elevation, gradient, and channel width when land was classified by geology and geomorphic processes (Fausch et al. 1988).

Relatively recent technological advances allow regional-scale analysis of habitat influences on fish populations. The emerging use of GIS technology to quantify landscape-scale variables and develop landscape-scale models incorporating GIS data provide a powerful tool to further understand landscape- and site-scale habitat influences on fish populations over large, hydrologically diverse geographic areas. This understanding can help direct management activities to habitats where beneficial results are most likely and away from lessinfluential habitat attributes. However, because these landscape tools are a relatively recent innovation and statewide fish and habitat databases are relatively limited, multivariate analysis encompassing a spatial scale and habitat variability of this extent also is rare (Lyons 1996; Terrell et al. 1996; Zorn et al. 2002).

The objective of our study was to determine the feasibility of using landscape-scale habitat variables derived from GIS data to explain the variation in the density of five common sport fishes in Michigan rivers: brook trout Salvelinus fontinalis, brown trout Salmo trutta, Chinook salmon Oncorhynchus tshawytscha, steelhead O. mykiss (anadromous rainbow trout), and white sucker $\mathrm{Ca}$ tostomus commersonii. We compared the relative variation in density across species explained by landscape-scale habitat models with that explained by models fitted with more traditional site-scale habitat variables.

\section{Methods}

Data sources.-We used a regional fish and habitat database, the Michigan Rivers Inventory (MRI), to address our objective and increase the applicability of the regression models. Ideally, models based on this large-scale database would allow estimates of fish density to be made for streams throughout lower Michigan and other areas with similar watershed characteristics. The MRI includes site-based fish population estimates and habitat data collected between 1970 and 2000 at several hundred sites in Michigan's Lower Peninsula. Included for each site were GIS-based map data such as characterizations of land use and geology for the catchment and combinations of actual and modeled data for key habitat parameters such as July temperature and exceedence flows (Seelbach and Wiley 1997). The GIS framework and georeferenced relational database allowed each MRI sampling location to be related to available habitat data at the landscape (catchment area) and site-specific (100-300-m) scales.

Dependent variable: fish density.-Population estimates of fish density (number/ha) generated 


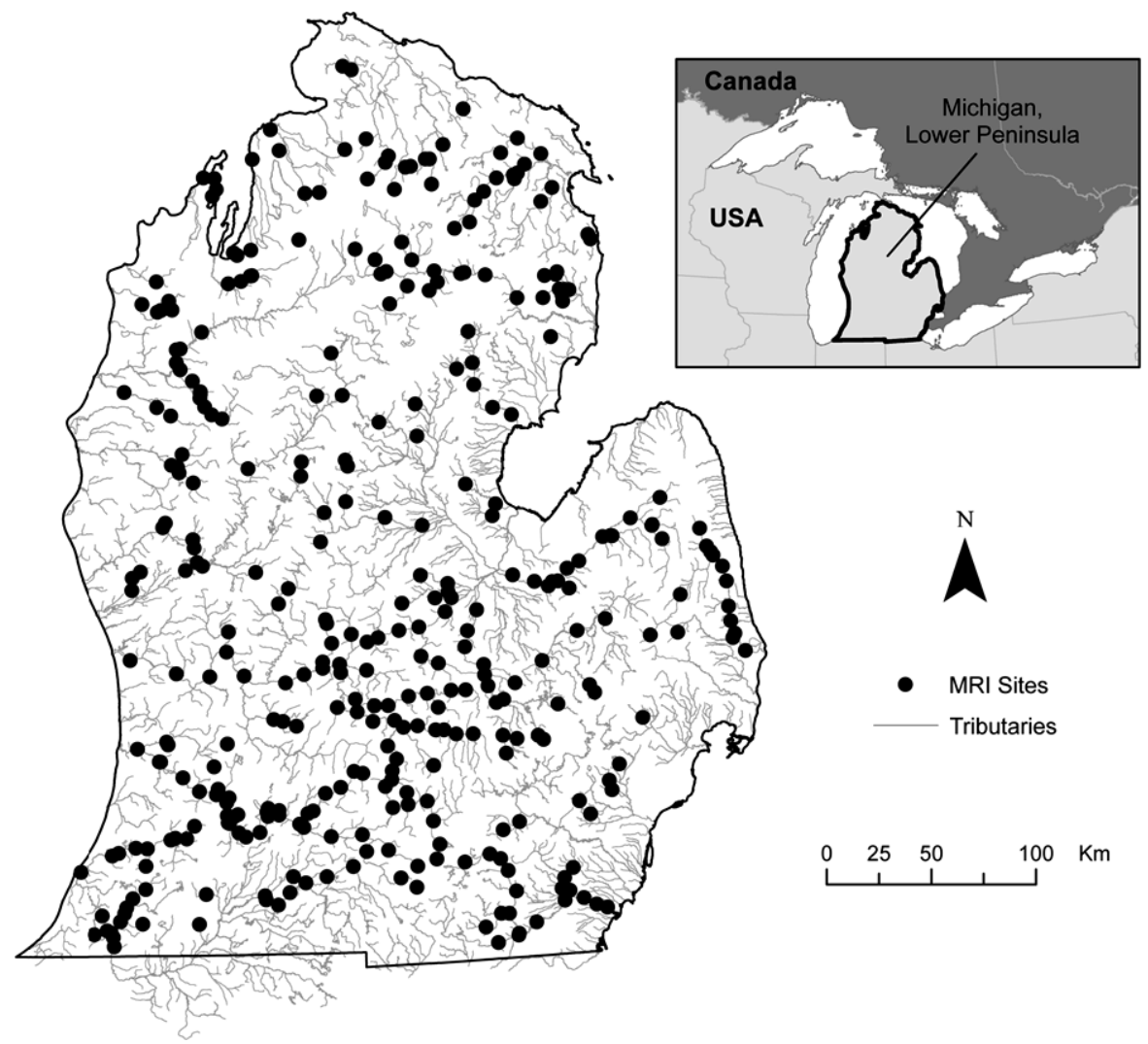

FIgURE 1.- Map showing the locations of the 321 fish data sites in Michigan's Lower Peninsula used in multiple linear regression analysis.

from multiple-pass depletion electrofishing and rotenone sampling from 1970 to 2000 were available at 301 MRI sites (Seelbach and Wiley 1997). Additional data were obtained from University of Michigan surveys and Michigan Department of Natural Resources Fisheries Division records. These increased the number of sites with fish density data used in our study to 321 (Figure 1). The number of sites with data for each individual species varied (Table 1) because species occurrence differed among sites and some streams were sampled only for salmonines.
As fish sampling at the MRI and other sites in our study occurred during summer, the population structure of the fishes represented varied depending on the life cycles of the species studied and the locations of the sample sites. Brook trout, brown trout, and white suckers were sampled primarily in landlocked streams and represented resident populations with both juveniles and adults present during summer sampling. (Several sites for which the year of fish sampling corresponded with known brown trout stocking were removed from our brown trout analysis.) Other study species,

TABLE 1.- Summary of species occurrence and density (number/ha) data for species included in this study of Michigan's Lower Peninsula rivers. Density values were calculated only for sites at which the species in question was present.

\begin{tabular}{lcccccr}
\hline & \multirow{2}{*}{$\begin{array}{c}\text { Number of sites } \\
\text { with species }\end{array}$} & $\begin{array}{c}\text { Number of sites } \\
\text { where species }\end{array}$ & \multicolumn{5}{c}{ Density } \\
\cline { 4 - 7 } density data & was present & Minimum & Maximum & Mean & SD \\
\hline Brook trout & 303 & 74 & 0.8 & 8,855 & 1,224 & 1,697 \\
Brown trout & 318 & 112 & 0.9 & 7,567 & 1,078 & 1,566 \\
Chinook salmon & 293 & 20 & 0.7 & 1,818 & 157 & 405 \\
Steelhead & 303 & 66 & 2.2 & 6,728 & 845 & 1,380 \\
White sucker & 268 & 218 & 0.5 & 7,647 & 488 & 901 \\
\hline
\end{tabular}


TABLE 2.-Variables used in multiple linear regression analysis for five fish species at 321 sites on Michigan rivers. Type indicates both the source of the data $(\mathrm{M}=$ measured; $\mathrm{C}=$ combination of measured and predicted $)$ and the transformation(s) used in the models $\left(1=\log _{10}[x]\right.$ and $\left\{\log _{10}[x]\right\}^{2} ; 2=x$ and $\log _{10}[x] ; 3=x$ and $x^{2} ;$ and $\left.4=\arcsin [x]\right)$.

\begin{tabular}{|c|c|c|c|c|c|c|c|c|}
\hline \multirow[b]{2}{*}{ Scale } & \multirow[b]{2}{*}{ Variable } & \multirow[b]{2}{*}{ Description } & \multirow[b]{2}{*}{$N$} & \multicolumn{4}{|c|}{ Values } & \multirow[b]{2}{*}{ Type } \\
\hline & & & & Minimum & Maximum & Mean & $\mathrm{SD}$ & \\
\hline \multirow[t]{5}{*}{ Landscape } & DA & Drainage area $\left(\mathrm{km}^{2}\right)$ & 321 & 2.16 & $7,800.0$ & 726.8 & $1,161.1$ & M-1 \\
\hline & LFY & $\begin{array}{l}90 \% \text { Exceedence flow yield } \\
\left(\mathrm{m}^{3} \cdot \mathrm{s}^{-1} \cdot \mathrm{km}^{-2}\right)\end{array}$ & 321 & $<0.00$ & 1.09 & 0.15 & 0.16 & C-2 \\
\hline & Temp & Mean July temperature $\left({ }^{\circ} \mathrm{C}\right)$ & 319 & 12.41 & 26.40 & 20.45 & 2.80 & $\mathrm{C}-3$ \\
\hline & Temp flux & $\begin{array}{l}\text { July weekly temperature } \\
\text { fluctuation }\left({ }^{\circ} \mathrm{C}\right)\end{array}$ & 319 & 2.11 & 16.85 & 7.83 & 1.82 & $\mathrm{C}$ \\
\hline & Gradperc & Channel gradient (\%) & 321 & 0.00 & 5.12 & 0.21 & 0.47 & M-4 \\
\hline \multirow[t]{6}{*}{ Site } & Depth & Depth $(\mathrm{m})$ & 321 & 0.02 & 1.37 & 0.46 & 0.26 & $\mathrm{C}-2$ \\
\hline & Velocity & Velocity (m/s) & 321 & 0.00 & 2.94 & 0.27 & 0.33 & $\mathrm{C}-2$ \\
\hline & Gradient & $\begin{array}{l}\text { Channel gradient in the field } \\
(\mathrm{ft} / \mathrm{mi})^{\mathrm{a}}\end{array}$ & 225 & 0.00 & 30.0 & 2.53 & 4.96 & M-2 \\
\hline & Bank cover & $\begin{array}{l}\text { Bank within } 0-3 \mathrm{~m} \text { of channel } \\
\text { as brush, deciduous or } \\
\text { coniferous forest }(\%)\end{array}$ & 229 & 0.00 & 100.0 & 77.77 & 29.33 & M-4 \\
\hline & Softsub & $\begin{array}{l}\text { Substrate as sand or finer } \\
\text { material }(\%)\end{array}$ & 258 & 0.00 & 100.0 & 58.06 & 29.32 & M-4 \\
\hline & Rocksub & $\begin{array}{l}\text { Substrate as gravel, cobble, or } \\
\text { boulder }(\%)\end{array}$ & 258 & 0.00 & 90.00 & 38.65 & 21.24 & M-4 \\
\hline
\end{tabular}

a $1 \mathrm{ft} / \mathrm{mi} \approx 19 \mathrm{~cm} / \mathrm{km}$.

such as Chinook salmon and steelhead, only occurred in areas accessible to the Great Lakes. As various life stages of these species emigrate to the lake, not all are present during summer. Adult Chinook salmon migrate up rivers to spawn in the fall, their fry hatch in March through early April, and nearly all leave by June (Carl 1980). Because Chinook salmon smolts tend to leave rivers before midsummer (Carl 1980; USFWS 1982), the regression models using MRI data were based on few sites $(n<20)$ sampled before complete outmigration. Steelhead adults return to the lake immediately after spawning, and most are gone by mid-June. Juvenile steelhead generally remain in the streams for 1-3 years before emigrating to the Great Lakes (USFWS 1982; Raleigh et al. 1984; Seelbach 1993), so the regressions for them were based primarily on populations ranging from 0 to 2 years of age. Nine MRI sites above dams on the Au Sable River and the Pine River (the latter a tributary to the Manistee River) did have resident rainbow trout populations. Because these sites contain high-quality populations with suitable habitat and are not stocked with this species, they were included with the steelhead sites for analysis.

Independent variables: landscape and site-scale habitat.-The independent habitat variables chosen for fish density modeling were divided into two groups based on spatial scale, landscape or site (Table 2). The variables classified as landscape scale were those that could be obtained through analysis of GIS maps and catchment-scale data and models. These variables were drainage area $\left(\mathrm{km}^{2}\right)$, LFY $\left(\mathrm{m}^{3} \cdot \mathrm{s}^{-1} \cdot \mathrm{km}^{-2}\right)$, percent channel gradient, mean July temperature $\left({ }^{\circ} \mathrm{C}\right.$; defined as the average of the weekly maximum and minimum values for the month), and July weekly temperature fluctuation (maximum less minimum). Drainage area and percent channel gradient were measured directly from GIS-based maps. Values for LFY were obtained from U.S. Geological Survey gauging stations at $5 \%$ of our sites; at the remaining sites, they were predicted from catchment-scale data on variables including drainage area, precipitation, mean catchment slope, and various categories of quaternary geology, soil texture, and land cover or use (P. Seelbach, Michigan Department of Natural Resources, unpublished data). Mean July temperature and July weekly temperature fluctuation were measured at $51 \%$ of our study sites. At the others they were predicted from models developed for estimating July maximum and minimum temperatures that included primarily catchment- (e.g., surficial geology, land cover or use, channel width or area, riparian shading, and groundwater velocity) and reach-scale variables (Wehrly et al. 1998).

Although temperature and flow are routinely measured in the field, we classified them as landscape-scale habitat features because the above modeling showed them to be predictable from GIS catchment- and reach-scale data and because their inclusion was consistent with our study objective 
of specifically examining GIS-based, landscapescale predictions. We included quadratic transformations of mean July temperature and drainage area in our analyses to account for the intermediate preferences for these variables by several study species.

The habitat variables classified as site scale were those traditionally measured in field surveys. Because most of these variables cannot be measured or predicted using GIS analysis and require visits to the site, site-scale habitat data were not available at all 321 fish sites (Table 2). The site-scale variables used were depth $(\mathrm{m})$, velocity $(\mathrm{m} / \mathrm{s})$, bank cover (percent riparian brush cover within 3 $\mathrm{m}$ of the upland bank), gradient ( $\mathrm{ft} / \mathrm{mi}[1 \mathrm{ft} / \mathrm{mi} \approx$ $19 \mathrm{~cm} / \mathrm{km}$ ]; measured in the field), and percent of substrate type (organic matter, clay, silt, sand, gravel, cobble, boulders, and bedrock). When depth and velocity measurements were not available from the field, they were obtained from a model predicting the values that would occur at the $90 \%$ exceedence flow of each site. This was to ensure that depth and velocity were not measured or predicted for extreme events such as floods. Sediment categories were combined for analysis; "rocksub" included gravel, cobble, and boulders, whereas "softsub" included sand and finer substrates. Because the sum of rocksub and softsub always equaled 100 , only softsub was entered into models. These five site-scale variables were chosen because they were available at the largest number of sites and were important predictors in other studies (Gordan and MacCrimmon 1982; Raleigh et al. 1986; Fausch et al. 1988). The bank cover and softsub variables were normalized by means of an arcsine transformation.

Multiple linear regression modeling.-Multiple linear regression models estimating fish density for the five study species were developed individually for each habitat scale. For most species, the large number of sites with zero values for fish density (Table 1) highly skewed the data, and removal of zero-density sites helped to normalize them. Regression analysis was run using only sites at which the species of interest was present to better predict and understand habitat characteristics where the species was abundant rather than those influencing presence or absence. Thus, the number of sites used in regression models varied by species, ranging from 20 to 218 (Table 1). The modeling procedures for each habitat scale and species were the same. For all analyses, results with $P \leq 0.05$ were considered significant.

Pearson's correlations were first computed among the physical habitat variables from all 321 sites to indicate possible collinear relationships within each scale. Collinearity among independent variables can lead to higher predictive power than is actually present (artificially high $R^{2}$ ), and biased regression coefficients that may be unstable and have large variances and unexpected signs (Farrar and Glauber 1967; Belsley et al. 1980; MitchellOlds and Shaw 1987; Neter et al. 1996). We kept correlated variables in our initial regression analysis to avoid misspecification bias and a loss of explanatory power (Farrar and Glauber 1967; Carnes and Slade 1988; James and McCulloch 1990). Although Pearson's correlation values were not used as a variable selection technique, they were useful for exploratory analysis and provided valuable information for understanding the relationships among our independent variables and interpreting model results and subsequent collinearity analyses.

We computed condition indices (CI) and variance-decomposition proportions as indices of collinearity among the variables in each model. Unlike Pearson's correlations, these measures allow determination of collinear relationships among three or more variables, which may not be apparent when looking only at two variables. Condition indices are calculated using the eigenstructure of the predictor variable cross-products matrix $\left(\mathbf{X}^{\prime} \mathbf{X}\right)$; they are the square roots of the ratio of the largest eigenvalues to each individual eigenvalue. The smaller the minimum individual eigenvalue is relative to the maximum (i.e., the larger the value of CI), the higher the degree of collinearity (Belsley et al. 1980; Carnes and Slade 1988; Beauchamp et al. 1992). The CI with the largest value is also called the condition number $(\mathrm{CN})$. When the data matrix is stable and there is no collinearity, the eigenvalues, $\mathrm{CI}$, and $\mathrm{CN}$ will equal one; as the $\mathrm{CI}$ and $\mathrm{CN}$ values increase, so does collinearity. A high $\mathrm{CN}$ alone does not imply collinearity. In addition, there must be relatively high variancedecomposition proportions (VP) associated with two or more coefficients having large CIs; these VP indicate collinear variables that may be impacting the coefficient estimates (Belsley et al. 1980). Literature suggests that matrices are most stable and variables are uncorrelated when CI $<$ 10; moderate correlations among variables begin to appear when CI $>30$, and CI $>100$ (when associated with VP $>0.50$ ) indicates biased regression estimates with large variances (Belsley et al. 1980; Carnes and Slade 1988; Beauchamp et al. 1992). We chose a moderate cutoff value of 20 
TABLE 3.- Pearson product-moment correlation matrix of landscape- and site-scale habitat variables (see Table 2) used in regression models. Correlations significant at the $P<0.05$ level are shown in bold italics, and those higher than 0.50 are marked with asterisks.

\begin{tabular}{|c|c|c|c|c|c|c|c|c|c|c|c|}
\hline Scale & $\begin{array}{c}\text { Habitat } \\
\text { variable }\end{array}$ & $\mathrm{DA}^{\mathrm{a}}$ & LFY & Temp flux & Temp & Gradperc & Gradient & Softsub & Depth & Velocity & $\begin{array}{l}\text { Bank } \\
\text { cover }\end{array}$ \\
\hline \multirow[t]{5}{*}{ Landscape } & $\mathrm{DA}^{\mathrm{a}}$ & 1.00 & & & & & & & & & \\
\hline & LFY & -0.14 & 1.00 & & & & & & & & \\
\hline & Temp flux & -0.12 & -0.35 & 1.00 & & & & & & & \\
\hline & Temp & $0.76^{*}$ & $-0.50 *$ & 0.11 & 1.00 & & & & & & \\
\hline & Gradperc & -0.45 & 0.15 & -0.09 & -0.49 & 1.00 & & & & & \\
\hline \multirow[t]{5}{*}{ Site } & Gradient & -0.03 & 0.03 & 0.08 & -0.01 & 0.16 & 1.00 & & & & \\
\hline & Softsub & -0.31 & -0.10 & 0.14 & -0.11 & -0.14 & -0.18 & 1.00 & & & \\
\hline & Depth & $0.79 *$ & -0.05 & -0.25 & $0.54^{*}$ & -0.34 & -0.12 & -0.11 & 1.00 & & \\
\hline & Velocity & -0.03 & 0.40 & -0.35 & -0.27 & -0.06 & 0.03 & 0.03 & 0.14 & 1.00 & \\
\hline & Bank cover & 0.08 & 0.19 & -0.18 & -0.06 & -0.08 & 0.03 & -0.04 & 0.11 & 0.06 & 1.00 \\
\hline
\end{tabular}

${ }^{\mathrm{a}} \log _{10}$ transformed.

for the CI in the presence of a 0.50 and higher VP because we were most interested in which variables best explained the statewide variation in fish densities rather than the exact coefficient estimates. We identified the variables involved in the collinear relationship as those with associated variance proportions higher than 50\% (Belsley et al. 1980).

We used the "all subsets" regression method to look at all possible combinations of the five variables for each habitat scale to determine the model that explained the greatest variation in each species' density (James and McCulloch 1990; Graham 2003). Model runs started with one independent habitat variable; additional variables were then added to look at all possible combinations of 2-5 variables. Residuals were examined for normality and homogeneity of variance. Variables were transformed when necessary to meet the assumptions of normality and homogeneity of variance (Table 2). Models were considered significant only if both the regression and coefficient $P$-values were less than 0.05 . We reduced the set of significant models by eliminating those for which collinearity may have harmed the regression estimates. Of the significant models for each species, the best-fit models for each habitat scale were those with significant coefficients and the highest adjusted- $R^{2}$ values. If two significant models for the same species had the same adjusted $R^{2}$, the one with the lower standard error of the estimate was chosen. Best-fit models could not have both a $\mathrm{CN}$ higher than 20 and two or more associated VP higher than 0.50 .

\section{Results \\ Landscape-Scale Fish Density Models}

Significant correlations occurred among all of the landscape-scale variables used in modeling, with the exception of July weekly temperature fluctuation and percent channel gradient (Table 3). The strongest positive correlation for landscapescale variables was between mean July temperature and $\log _{10}$ drainage area $(r=0.76 ; P<0.001)$. The strongest negative correlations were between mean July temperature and LFY $(r=-0.50 ; P<$ 0.001 ) and mean July temperature and percent channel gradient $(r=-0.49 ; P<0.001)$.

The amount of spatial variation in fish density explained by the best-fit landscape-scale models ranged from $18 \%$ for steelhead to $69 \%$ for Chinook salmon (Table 4). The most commonly occurring landscape-scale variable in the best-fit models was mean July temperature. The density of both brook trout and brown trout was negatively related to mean July temperature. Chinook salmon density was positively related to LFY and negatively related to mean July temperature. Steelhead density was negatively related to drainage area and positively related to LFY. A positive relationship with LFY suggests a preference for streams with higher base flows, which probably also have higher groundwater contributions. White sucker density was negatively related to drainage area (Table 4). July weekly temperature fluctuation and percent channel gradient did not appear in any of the bestfit models.

We report details of model fitting here for brown trout and Chinook salmon to illustrate the process of landscape-scale model analysis and selection used for all five species. A total of nine landscapescale regression models of brown trout density were significant, including all models with single habitat variables (Table 5). Mean July temperature explained the most variation in brown trout density; inclusion of both forms of the temperature variable explained an additional $5 \%$ of the varia- 
tion but this model was not selected as the best fit due to the high condition number and resulting wide confidence intervals for the coefficients (Table 6). No other habitat variables were significant when mean July temperature was included, as was also the case for the steelhead models. Drainage area, LFY, and percent channel gradient together accounted for $27 \%$ of the variation in brown trout density; these three variables did not exhibit collinearity using our standards.

The density of Chinook salmon parr was negatively related to mean July temperature and positively related to LFY in the best-fit regression model (Table 4). Seven additional models, including ones with 1-2 habitat variables, explained from $29 \%$ to $62 \%$ of the variation in Chinook salmon densities (Tables 4, 5). Drainage area and mean July temperature, two strongly correlated variables $(r=0.76)$, were significant predictors of Chinook salmon density individually. When both variables were entered into the Chinook salmon models, neither was significant, as is often the result of collinearity $(\mathrm{CN}=25.3$; VP: intercept $=0.96$; drainage area $=0.85$; mean July temperature $=0.99$ ).

\section{Site-Scale Fish Density Models}

The number of fish sampling sites that had sitescale habitat data available ranged from 225 for channel gradient measured in the field to 321 for depth and velocity (Table 2). Therefore, the number of sites for each site-scale regression varied depending on the variables entered and the species modeled. Significant correlations existed among two sets of habitat variables within the site scale: channel gradient measured in the field and softsub $(r=-0.18 ; P<0.02)$, and velocity and depth $(r$ $=0.14 ; P<0.02)$ (Table 3$)$. These few correlations resulted in no site-scale models with a $\mathrm{CN}$ greater than 20 .

Only three of the five site-scale habitat variables (depth, velocity, and softsub) were significant in explaining the variation in fish density (Table 5). Depth was negatively correlated with the density of all five species and was the only significant variable for all species except white sucker, whose best-fit model also included softsub (Table 4). Depth alone accounted for $12 \%$ of the density variation for brook trout and steelhead and up to $57 \%$ of that for Chinook salmon.

\section{Scale Comparisons}

For all species, more variation in fish density was explained by the landscape-scale habitat data than by the site-scale data (Table 4). Steelhead models had the lowest adjusted- $R^{2}$ values at both spatial scales, while Chinook salmon models had the highest. Several landscape- and site-scale habitat variables were significantly correlated with each other (Table 3). Depth, which appeared in all best-fit site-scale models, was strongly correlated with $\log _{10}$ drainage area (0.79) and mean July temperature (0.54) and less strongly correlated with July weekly temperature fluctuation and percent channel gradient. Mean July temperature, the most common variable in landscape-scale models, was also correlated with velocity $(r=-0.27 ; P<$ $0.001)$, as was LFY ( $r=0.40 ; P<0.001)$.

\section{Discussion}

For our five fish species, landscape-scale habitat data obtained from GIS map analysis and models explained more spatial variation in fish density than site-scale habitat data collected in the field. When samples are collected across broad regions, large regional gradients in key factors (e.g., hydrology, geology, climate, water temperature, and zoogeography) often drive the large-scale spatial patterns in the distribution and abundance of stream fishes. For example, in Australian streams, landscape-scale features described most of the variation in species assemblages and density, and while site-scale variables did have an effect they explained little additional variation in the data $(\mathrm{Pu}-$ sey et al. 2000).

When landscape features drive the key factors affecting fish (e.g., temperature), it becomes economically feasible to predict species distribution and abundance using GIS technology and statistical models once the site- and landscape-scale data needed for model development have been collected. These types of models can save time and money by making efficient use of site-scale data that have already been collected. Still, there are limits to the level of prediction that can occur when landscape-scale data are used. For example, landscape-scale studies can suggest general habitat constraints and linkages to key local-scale habitat features, while long-term studies on smaller spatial scales can better identify biotic interactions such as predation and competition and impacts of habitat degradation that may not be evident at the landscape scale (Levin 1992; Jackson et al. 2001). Thus, the two habitat scales complement each other well.

\section{Significant Landscape-Scale Predictor Variables}

This study demonstrated that landscape-scale habitat features obtained through GIS analysis, 
TABLE 4.-Landscape- and site-scale best-fit regression models for five fishes in Michigan rivers. All regression models predicted fish density (number/ha), which was $\log _{10}$ transformed, and were significant at the 0.01 level. See Table 2 for definitions of the independent variables; see text for definitions of condition number and variance proportion.

\begin{tabular}{|c|c|c|c|c|c|}
\hline Scale & Species & df & Variables & Coefficients (SEs) & $P$ \\
\hline \multirow[t]{12}{*}{ Landscape } & \multirow[t]{2}{*}{ Brook trout } & \multirow[t]{2}{*}{72} & Intercept & $4.609(0.459)$ & $<0.00$ \\
\hline & & & $\mathrm{Temp}^{2}$ & $-6.76 \cdot 10^{-3}(0.001)$ & $<0.00$ \\
\hline & \multirow[t]{2}{*}{ Brown trout } & \multirow[t]{2}{*}{111} & Intercept & $5.009(0.293)$ & $<0.00$ \\
\hline & & & Temp $^{2}$ & $-7.30 \cdot 10^{-3}(0.001)$ & $<0.00$ \\
\hline & \multirow[t]{3}{*}{ Chinook salmon } & \multirow[t]{3}{*}{19} & Intercept & $4.092(0.417)$ & $<0.00$ \\
\hline & & & $\log _{10}(\mathrm{LFY})$ & $0.667(0.296)$ & $<0.04$ \\
\hline & & & Temp $^{2}$ & $-0.006(0.001)$ & $<0.00$ \\
\hline & \multirow[t]{3}{*}{ Steelhead } & \multirow[t]{3}{*}{65} & Intercept & $2.729(0.337)$ & $<0.00$ \\
\hline & & & $\log _{10}(\mathrm{DA})$ & $-0.372(0.134)$ & $<0.01$ \\
\hline & & & LFY & $1.304(0.476)$ & $<0.01$ \\
\hline & \multirow[t]{2}{*}{ White sucker } & \multirow[t]{2}{*}{217} & Intercept & $3.090(0.114)$ & $<0.00$ \\
\hline & & & {$\left[\log _{10}(\mathrm{DA})\right]^{2}$} & $-0.132(0.14)$ & $<0.00$ \\
\hline \multirow[t]{11}{*}{ Site } & \multirow[t]{2}{*}{ Brook trout } & \multirow[t]{2}{*}{73} & Intercept & $3.097(0.203)$ & $<0.00$ \\
\hline & & & Depth & $-1.790(0.545)$ & $<0.01$ \\
\hline & \multirow[t]{2}{*}{ Brown trout } & \multirow[t]{2}{*}{111} & Intercept & $3.220(0.168)$ & $<0.00$ \\
\hline & & & Depth & $-1.954(0.392)$ & $<0.00$ \\
\hline & \multirow[t]{2}{*}{ Chinook salmon } & \multirow[t]{2}{*}{19} & Intercept & $2.664(0.249)$ & $<0.00$ \\
\hline & & & Depth & $-2.694(0.531)$ & $<0.00$ \\
\hline & \multirow[t]{2}{*}{ Steelhead } & \multirow[t]{2}{*}{65} & Intercept & $2.899(0.222)$ & $<0.00$ \\
\hline & & & Depth & $-1.595(0.505)$ & $<0.01$ \\
\hline & \multirow[t]{3}{*}{ White sucker } & \multirow[t]{3}{*}{196} & Intercept & $2.518(0.201)$ & $<0.00$ \\
\hline & & & Depth & $-1.213(0.217)$ & $<0.00$ \\
\hline & & & Arcsin (softsub) & $5.106 \cdot 10^{-3}(0.003)$ & $<0.05$ \\
\hline
\end{tabular}

particularly drainage area, hydrology, and temperature, were useful predictors of species abundance across large geographic areas encompassing a wide variety of stream types. Other studies of these species have also found these three characteristics to be suitable predictors of fish distribution and abundance within single-stream systems or small regions (Curry and Spacie 1979; Fausch et al. 1988; Lyons 1996; Stoneman and Jones 2000).

Temperature is a key variable for understanding salmonine abundance patterns across large regions. As in other studies of trout abundance and survival (Hinz and Wiley 1997; Connor et al. 2003; Wehrly et al. 2003), the brook trout, brown trout, and Chinook salmon densities in our models were negatively correlated with stream temperature. In our study, mean July temperature also explained a large percent of the spatial variation in steelhead density, but slightly more variation was explained by drainage area and LFY when temperature was not included in the subset of variables entered into regression analysis. Drainage area and LFY were correlated with temperature and are consistent with the known habitat preferences of this species. Mean July temperature was also significantly correlated with white sucker density, although more variation was explained by other habitat variables.
Because temperature is such a key variable for many fish species, we realize that our classification of temperature as a landscape-scale variable may have influenced our conclusions about which habitat scale was most useful for explaining spatial density variations. The site-scale models for brook trout and brown trout would have been most improved by the inclusion of temperature, explaining an additional $11 \%$ and $13 \%$ of the variation over that explained by depth. If temperature were classified as a site-scale variable, the best-fit site-scale models for brook trout and brown trout would explain $2 \%$ and $13 \%$ more variation than the bestfit landscape-scale model. Temperature is thus an extremely important variable influencing brown trout density across large geographic areas. Landscape-scale models for Chinook salmon, steelhead, and white sucker without mean July temperature would still explain more of the density variation than site-scale models with it. This indicates that regardless of how temperature is classified, other landscape-scale features are important determinants of density for these species. Temperature would only increase the variation explained by the site-scale models for these species by $2-5 \%$ over those with depth. In addition, because we modeled only sites where the species occurred, we did not see the strong effect of tem- 
TABLE 4.-Extended.

\begin{tabular}{|c|c|c|c|c|c|c|}
\hline \multirow[b]{2}{*}{ Species } & \multicolumn{2}{|c|}{$95 \%$ confidence limits } & \multirow[b]{2}{*}{ Adjusted $R^{2}$} & \multirow[b]{2}{*}{ SE } & \multirow[b]{2}{*}{ Condition number } & \multirow{2}{*}{$\begin{array}{l}\text { Variance } \\
\text { proportions }\end{array}$} \\
\hline & Lower & Upper & & & & \\
\hline \multirow[t]{2}{*}{ Brook trout } & 3.69 & 5.52 & 0.23 & 0.78 & 9.9 & 0.99 \\
\hline & -0.01 & -0.004 & & & & 0.99 \\
\hline \multirow[t]{2}{*}{ Brown trout } & 4.43 & 5.59 & 0.41 & 0.65 & 9.4 & 0.99 \\
\hline & -0.009 & -0.006 & & & & 0.99 \\
\hline \multirow[t]{3}{*}{ Chinook salmon } & 3.21 & 4.97 & 0.69 & 0.42 & 10.6 & 0.92 \\
\hline & 0.04 & 1.29 & & & & 0.05 \\
\hline & -0.008 & -0.003 & & & & 0.96 \\
\hline \multirow[t]{3}{*}{ Steelhead } & 2.06 & 3.40 & 0.18 & 0.83 & 7.1 & 0.96 \\
\hline & -0.64 & -0.11 & & & & 0.90 \\
\hline & 0.35 & 2.25 & & & & 0.11 \\
\hline \multirow[t]{2}{*}{ White Sucker } & 3.48 & 4.27 & 0.29 & 0.71 & 8.1 & 0.98 \\
\hline & -0.81 & -0.52 & & & & 0.98 \\
\hline \multirow{2}{*}{ Brook trout } & 2.69 & 3.50 & 0.12 & 0.84 & 3.9 & 0.94 \\
\hline & -2.88 & -0.70 & & & & 0.94 \\
\hline \multirow[t]{2}{*}{ Brown trout } & 2.89 & 3.55 & 0.18 & 0.77 & 4.4 & 0.95 \\
\hline & -2.73 & -1.18 & & & & 0.95 \\
\hline \multirow{2}{*}{ Chinook salmon } & 2.14 & 3.19 & 0.57 & 0.50 & 4.2 & 0.95 \\
\hline & -3.81 & -1.58 & & & & 0.95 \\
\hline \multirow[t]{2}{*}{ Steelhead } & 2.46 & 3.34 & 0.12 & 0.86 & 3.96 & 0.94 \\
\hline & -2.60 & -0.59 & & & & 0.94 \\
\hline \multirow{3}{*}{ White sucker } & 2.12 & 2.92 & 0.16 & 0.77 & 7.58 & 0.99 \\
\hline & -1.64 & -0.79 & & & & 0.41 \\
\hline & 0.00 & 0.01 & & & & 0.72 \\
\hline
\end{tabular}

TABLE 5.-Signs of coefficients and adjusted- $R^{2}$ values (SEs in parentheses) for models with variables that were significant predictors of fish density when entered alone. See Table 2 for variable definitions. Coefficient values are not shown because different forms of the variables were entered, depending on the transformation needed for the species. Bold italics indicate variables included in the best-fit model for that species.

\begin{tabular}{|c|c|c|c|c|c|c|}
\hline Scale & Habitat variable & Brook trout & Brown trout & Chinook salmon & Steelhead & White sucker \\
\hline \multirow[t]{9}{*}{ Landscape } & $\begin{array}{l}\text { DA } \\
\quad \text { Sign } \\
\quad \text { Adjusted } R^{2}(\mathrm{SE})\end{array}$ & $0.21 \overline{(0.79)}$ & $0.22(0.75)$ & $\begin{array}{c}- \\
0.54(0.51)\end{array}$ & $0.10 \stackrel{-}{(0.87)}$ & $0.29 \overline{(0.71)}$ \\
\hline & LFY & & & & & \\
\hline & $\begin{array}{l}\text { Sign } \\
\text { Adjusted } R^{2} \text { (SE) }\end{array}$ & & $\stackrel{+}{+} 0.04(0.83)$ & $\stackrel{+}{+}+29(0.64)$ & $\stackrel{+}{+}+09(0.87)$ & $0.03(0.82)$ \\
\hline & Temp & & & & & \\
\hline & $\begin{array}{l}\text { Sign } \\
\text { Adjusted } R^{2} \text { (SE) }\end{array}$ & $\begin{array}{c}- \\
0.23(0.78)\end{array}$ & $0.41(0.65)$ & $0.62(0.49)$ & $\begin{array}{c}- \\
0.15(0.84)\end{array}$ & $0.18 \stackrel{-}{(0.76)}$ \\
\hline & Temp flux & & & & & \\
\hline & $\begin{array}{l}\text { Sign } \\
\text { Adjusted } R^{2} \text { (SE) }\end{array}$ & & & & & 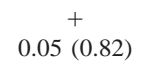 \\
\hline & Gradperc & & & & & \\
\hline & $\begin{array}{l}\text { Sign } \\
\text { Adjusted } R^{2} \text { (SE) }\end{array}$ & 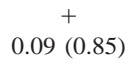 & $0.21^{+}(0.75)$ & $\begin{array}{c}+ \\
0.47(0.56)\end{array}$ & & $0.09 \stackrel{+}{(0.80)}$ \\
\hline \multirow[t]{6}{*}{ Site } & Depth at LFY & & & & & \\
\hline & $\begin{array}{l}\text { Sign } \\
\text { Adjusted } R^{2} \text { (SE) }\end{array}$ & $0.12 \stackrel{-}{(0.84)}$ & $0.18 \overline{(0.77)}$ & $\begin{array}{c}- \\
0.57(0.50)\end{array}$ & $0.12 \stackrel{-}{(0.86)}$ & $0.16(0.77)$ \\
\hline & Velocity at LFY & & & & & \\
\hline & $\begin{array}{l}\text { Sign } \\
\text { Adjusted } R^{2} \text { (SE) }\end{array}$ & & & & & $0.02 \stackrel{-}{(0.83)}$ \\
\hline & Softsub & & & & & \\
\hline & $\begin{array}{l}\text { Sign } \\
\text { Adjusted } R^{2} \text { (SE) }\end{array}$ & & & & & $\stackrel{+}{0.03(0.82)}$ \\
\hline
\end{tabular}


TABLE 6.-Significant landscape-scale models that were eliminated as the best fit because they did not meet collinearity standards for the condition number and variance proportions. See Table 2 for variable definitions. No significant models for Chinook salmon and steelhead had a condition number greater than 20.

\begin{tabular}{|c|c|c|c|c|c|c|c|c|c|c|}
\hline \multirow[b]{2}{*}{ Species } & \multirow[b]{2}{*}{ df } & \multirow[b]{2}{*}{ Variables } & \multirow{2}{*}{$\begin{array}{l}\text { Coefficients } \\
\text { (SEs) }\end{array}$} & \multirow[b]{2}{*}{$P$} & \multicolumn{2}{|c|}{$95 \%$ confidence limits } & \multirow{2}{*}{$\begin{array}{c}\text { Adjusted } \\
R^{2}\end{array}$} & \multirow[b]{2}{*}{$\mathrm{SE}$} & \multirow{2}{*}{$\begin{array}{c}\text { Condition } \\
\text { number }\end{array}$} & \multirow{2}{*}{$\begin{array}{c}\text { Variance } \\
\text { proportions }\end{array}$} \\
\hline & & & & & Lower & Upper & & & & \\
\hline \multirow[t]{3}{*}{ Brook trout } & \multirow[t]{3}{*}{72} & Intercept & $8.650(.972)$ & $<0.00$ & 6.71 & 10.59 & \multirow[t]{3}{*}{0.35} & \multirow[t]{3}{*}{0.71} & \multirow[t]{3}{*}{26.26} & 1.00 \\
\hline & & LFY & $-2.351(.594)$ & $<0.00$ & -3.54 & -1.17 & & & & 0.27 \\
\hline & & Temp & $-0.321(0.051)$ & $<0.00$ & -0.42 & -0.22 & & & & 0.99 \\
\hline \multirow[t]{3}{*}{ Brown trout } & \multirow[t]{3}{*}{111} & Intercept & $-8.053(3.90)$ & $<0.04$ & -15.8 & -0.33 & \multirow[t]{3}{*}{0.46} & \multirow[t]{3}{*}{0.62} & \multirow[t]{3}{*}{284.80} & 0.99 \\
\hline & & Temp $^{2}$ & $-0.046(0.01)$ & $<0.00$ & -0.07 & -0.02 & & & & 1.00 \\
\hline & & Temp & $1.428(0.425)$ & $<0.01$ & 0.59 & 2.27 & & & & 1.00 \\
\hline \multirow[t]{3}{*}{ White sucker } & \multirow[t]{3}{*}{216} & Intercept & $-15.544(5.120)$ & $<0.01$ & -25.7 & -5.45 & \multirow[t]{3}{*}{0.23} & \multirow[t]{3}{*}{0.73} & \multirow[t]{3}{*}{442.77} & 0.99 \\
\hline & & Temp & $1.822(0.475)$ & $<0.00$ & 0.89 & 2.76 & & & & 1.00 \\
\hline & & Temp $^{2}$ & $-0.046(0.011)$ & $<0.00$ & -0.07 & -0.02 & & & & 1.00 \\
\hline \multirow[t]{4}{*}{ White sucker } & \multirow[t]{4}{*}{215} & Intercept & $-16.409(4.738)$ & $<0.01$ & -25.8 & -7.1 & \multirow[t]{4}{*}{0.35} & \multirow[t]{4}{*}{0.68} & \multirow[t]{4}{*}{505.46} & 0.99 \\
\hline & & {$\left[\log _{10}(\mathrm{DA})\right]^{2}$} & $-0.107(0.017)$ & $<0.00$ & -0.14 & -0.07 & & & & 0.00 \\
\hline & & $\mathrm{Temp}^{2}$ & $-0.044(0.010)$ & $<0.00$ & -0.06 & -0.02 & & & & 1.00 \\
\hline & & Temp & $1.863(0.439)$ & $<0.00$ & 1.00 & 2.73 & & & & 1.00 \\
\hline
\end{tabular}

perature on presence/absence. Thus, our results present a conservative look at summer temperature influences.

Ninety percent exceedence flow yield, an index of base flows and water temperatures, was positively correlated with steelhead and Chinook salmon summer densities in our best-fit models. Raleigh et al. (1984) and Zorn et al. (2002) noted a positive relationship between annual flow regime characteristics and the quality of trout habitat, base flows being the most critical. Streams receiving a high percentage of flow from groundwater sources have more stable flows throughout the year and cooler summer temperatures, thereby providing more suitable salmonid habitat than streams that depend more on runoff (Fausch et al. 1988).

Drainage area was the most significant landscape-scale predictor for white sucker density. Curry and Spacie (1979) correlated the distribution of catostomids with stream drainage area and found that white suckers tended to occur further upstream than other sucker species. All species were negatively correlated with drainage area, probably reflecting higher densities of juveniles in small streams. Ninety percent exceedence flow yield and mean July temperature explained less variation in white sucker density because these fish can tolerate flashier streamflow conditions and have broad temperature tolerances (Scott and Crossman 1973; Walton 1980).

\section{Significant Site-Scale Predictor Variables}

The summer densities of all modeled species were negatively associated with depth in the sitescale models. Temperature increases with mean depth in Michigan trout streams; thus, depth acted as the best surrogate for temperature in the sitescale models. Mean depth also increases with drainage area, which was negatively associated with temperature and the density of several species. In addition, as salmonids grow, their preferred depth and velocity increases, and their territories increase in area (Allen 1969; Chapman and Brown 1969; Raleigh et al. 1984) as their density decreases, in what has been called the self-thinning process (Dunham and Vinyard 1997). These reasons may explain why depth accounted for more variation in summer fish density than any other site-scale variable and why fish density was inversely correlated with depth for all five species. By modeling the numeric density of salmonines, we were essentially modeling the density of small fish because small trout vastly dominate the catch in Michigan's Lower Peninsula trout streams. Angling was probably a very minor factor affecting fish density because small trout and salmon are protected under Michigan fishing regulations. Small white suckers are not typically targeted by stream anglers.

Substrate was a significant site-scale variable only for white sucker density. The positive relationship found between white suckers and softsub is likely because white suckers can better tolerate sites with very low gradient-and thus finer substrates and lower dissolved oxygen levels - than salmonines (Galloway and Kevern 1976; Trautman 1981; Wehrly et al. 2003).

\section{Model Assumptions and Limitations}

The best-fit regression models using GISderived, landscape-scale habitat data for each species in this study explained a relatively low and 
variable proportion of the variation in fish density. There is still a large amount of variation not accounted for by the habitat variables included in our analysis. However, our models have wide generality and are more robust because they were based on a large, regional database that better encompasses the range of variation in Michigan fish populations and habitat through time and space (Levins 1966; Fausch et al. 1988; Wiley et al. 1997). For example, in reviews of various fish models, the most precise models were constructed for data collected on short temporal or small spatial scales and were not applicable to other areas (Fausch et al. 1988; Terrell et al. 1996). Models with $R^{2}$ values higher than 0.75 (Fausch et al. 1988) and 0.60 (Terrell et al. 1996) often had low sample sizes ( $d f=22$ or less). Fausch et al. (1988) suggested that higher-quality models should have more than 20 degrees of freedom; in our models, df ranged from 65 to 217, with the exception of Chinook salmon. Furthermore, contrary to our models, many of the better-fitting models in Fausch et al. (1988) focused specifically on a single age or size range of fish. Individual life stages of fish typically have narrower habitat preferences, especially in regards to site-scale features for refuge, feeding, and spawning. Because of these differences, modeling all ages together may have reduced the predictive ability for each species' density.

Although the proportion of the variation in fish density explained by our landscape-scale, habitatbased regression models was generally low and variable, it was within the range of values reported for other areas and other stream fishes. For example, models using site-scale habitat variables to predict the density of smallmouth bass Micropterus dolomieu and largemouth bass M. salmoides in 19 Missouri streams had adjusted- $R^{2}$ values of 0.49 and 0.47, respectively (Sowa and Rabeni 1995). Pess et al. (2002) modeled the spawner abundance of coho salmon Oncorhynchus kisutch in the Snohomish River, Washington, basin using reach- and catchment-scale data collected over 14 years at 54 sites and obtained adjusted- $R^{2}$ values between 0.20 and 0.42. In Fausch et al. (1988), results for models of multiple ages and sizes of trout using a combination of habitat scales and more than 20 degrees of freedom, had $R^{2}$ values ranging from 0.28 to 0.52. Zorn et al. 2004 developed multiple linear regression models for 68 common species at sites throughout the Lower Peninsula of Michigan using both site- and landscape-scale habitat variables. The average adjusted- $R^{2}$ values for models using sites where the species occurred was 0.43 , only slightly higher than our average for only landscape-scale models.

Errors in our data set, such as measurement errors for both the dependent and independent variables measured in the field, also may have reduced our ability to explain the variation in density. The quality of the GIS-derived data was limited by the scale and accuracy of the base maps. Use of predicted temperature and $90 \%$ exceedence flows (at $49 \%$ and $95 \%$ of sites, respectively), along with depth and velocity, as model inputs represented an additional source of error and unexplained variance, and even measured temperature values represented conditions in only one summer (Wehrly et al. 1998). Temperature model predictions were generally within $1-2^{\circ} \mathrm{C}$ of actual weekly mean temperatures (Wehrly et al. 2003), but this amount of error can be significant for coldwater species when stream conditions approach their thermal tolerance limits. The model predicting 90\% exceedence flow had an $R^{2}$ of 0.96 (P. Seelbach, Michigan Department of Natural Resources, unpublished data) and provided estimates for streams of all sizes in Michigan, but considerable error occurred around the actual point estimates. Nevertheless, it was possible to use GIS-based, landscape-scale data to explain some variation in fish density. Drainage area, a key landscape-scale variable on its own, was also used in the model to predict $90 \%$ exceedence flow. Data independence issues were minimized because we used LFY, which is $90 \%$ exceedence flow standardized by drainage area. Inclusion of both variables in our model therefore allowed the separate influence of stream size (drainage area) and base flow/groundwater input (LFY) to be examined, since they influence fish density through different mechanisms.

The fit of our models also may have been low because habitat variables often did not exhibit clear linear relationships with measured fish densities. Several distributions were wedge-shaped, reflecting the dominant role of those variables as ecological limiting factors on fish density (Terrell et al. 1996; Thomson et al. 1996; Cade et al. 1999). Future work could apply quantile regression analysis to describe the relationships along the upper limits rather than at the center of the distribution, as in traditional multiple linear regression analysis (Terrell et al. 1996; Thomson et al. 1996; Cade et al. 1999; Wang et al. 2001). However, this provides only a univariate approach to looking at habitatfish abundance relationships. We did include quadratic transformations of mean July temperature 
and drainage area to account for the intermediate preference ranges for these variables, which create bell-shaped distributions. Inclusion of both linear and quadratic forms of mean July temperature in models did explain approximately 5\% more variation in brown trout and white sucker density than the quadratic form alone (Table 6), indicating that these two species may not have a linear relationship with temperature throughout the Lower Peninsula. However, the $\mathrm{CN}$ for models including both forms was more than 200 , indicating severe multicollinearity, which was further evidenced by the large $95 \%$ confidence intervals for the coefficients compared with those of the models with the quadratic form alone. Thus, although the quadratic form alone explained slightly less variation, we have comparatively more confidence in the precision of the coefficient estimates resulting from that form.

\section{Collinearity among Habitat Variables}

Collinearity among key habitat variables is generally unavoidable in river studies owing to the large-scale nature of these systems and the many interactions between landscape processes and sitescale habitat attributes (Frissell et al. 1986; Larsen et al. 1986; Wiley et al. 1997). While collinearity can lead to a loss of power, large variances around coefficients, and artificially inflated $R^{2}$ values (Farrar and Glauber 1967), eliminating correlated habitat variables could have obscured important differences in the correlated variables' relationship to the density of each species (Farrar and Glauber 1967). For example, correlated variables, such as flow and temperature, can influence fish survival and abundance through different mechanisms (Stoneman and Jones 2000; Connor et al. 2003; Zorn 2003), as we hypothesized in the Chinook salmon model. Not all variables that were highly correlated caused harmful levels of collinearity in our models. In addition, some collinear relationships were identified in models with large numbers of variables that were not evident from Pearson's correlations, such as mean temperature and temperature fluctuation in the brown trout models. Our analysis technique allowed exploration of each variable's contribution, while our use of the $\mathrm{CI}$ and VP insured that our selected best-fit model did not have severe collinearity (Belsley et al. 1980; Carnes and Slade 1988; Beauchamp et al. 1992) and thus low bias for the adjusted- $R^{2}$ and coefficient estimate values.

Our regression models would only be applicable to streams in which the species is known to be present because sites with zero density were excluded from our analysis. Elimination of zerodensity sites was needed to normalize the distribution of the species abundance data because less than $35 \%$ of the sites had the study species present (with the exception of the white sucker). Inclusion of zero values would have dramatically skewed the distribution of independent variables in each model and probably biased model fits, as Zorn et al. (2004) found with regression analysis of Michigan fishes using all available sites.

While the landscape and site-scale habitat features identified here were important, many other factors can influence fish abundance. Future work should seek to integrate the role of predation, competition, prey availability, and other biotic interactions with land use, watershed geology, and chemical water quality in determining the abundance of fish populations. Although Zorn et al. (2004) found that biotic factors were not important predictors of regional species abundance patterns in Michigan streams because of the huge hydrologic and temperature gradients that occur across the state, an understanding of the biotic influences on fish populations may provide additional insight into the mechanisms by which landscape-scale features actually affect fish abundance and distribution. The increased precision in models resulting from additional habitat variables and scales also must be weighed against the loss of spatial applicability and increased complexity and sampling costs (Fausch et al. 1988; Lyons 1996). Future work also should include refining and validating the present models by collecting more fish and habitat data. Because temporal variation may account for a large portion of the additional variation $(<40 \%)$ in fish abundance, additional modeling focused on long-term data sets of specific rivers could help improve fits or explain low model fits for some species (Wiley et al. 1997). However, this would require collection of additional temporal data such as temperature, discharge, and fish abundance.

\section{Summary and Management Implications}

The findings of our study indicate that coarse, landscape-scale measurements obtained from GIS analysis have utility for predicting the density of individual fish species, as Richards and Host (1994) demonstrated for macroinvertebrate assemblages. Recent studies indicate that an understanding of both landscape- and site-scale constraints on aquatic systems is essential for effective management of river fishes and habitat. For example, 
in mixed-forest and agricultural areas in Michigan, Richards et al. (1996) and Roth et al. (1996) found that stream characteristics such as woody debris and substrate composition were related more closely to local and riparian conditions while channel morphology and hydrologic characteristics were more influenced by catchment characteristics. In Wisconsin, Wang et al. (2002) found that for best management practices (BMPs) within the riparian area to be effective at improving stream habitat, the catchment must be in reasonably good condition or the local BMPs must be used in combination with catchment-scale ones. Thus, managers in Michigan's Lower Peninsula need to have an understanding of the status and impacts of both habitat scales before launching into site-scale management activities such as instream habitat improvement.

Our type of model could be very useful to managers who need to make low-cost or widespread decisions. The use of landscape-scale derived features as predictive variables also facilitates the application of these models to other streams in the Great Lakes basin, assuming that the quantitative relationship between the landscape-scale variables and the proximal variables they index are similar to those found in Michigan (Zorn et al. 2002). Researchers and managers from Wisconsin, Illinois, and Michigan are collaboratively developing models with similar landscape-scale input variables to apply to river valley segments throughout each state and enable regional summaries of current riverine ecological status and risk. Fisheries agencies have increasingly restricted time, money, and effort to put toward field surveys, which limits the number of streams that can be sampled. These models could be used as a first step in identifying streams for which more detailed site-scale surveys would be most beneficial. Model predictions could be used as benchmarks for comparison with actual survey data and for directing management effort to streams where there is a mismatch between predicted and observed species abundance. Still, care must be taken not to extrapolate outside of the values used in constructing these models.

\section{Acknowledgments}

This project was supported through a Great Lakes Protection Fund grant. We thank P. Seelbach, M. Wiley, and K. Wehrly for important background information and advice concerning the MRI database and analysis and numerous graduate students at the University of Michigan for use of their data. We also thank those in the GIS labo- ratory at the Institute for Fisheries Research for help with GIS-related issues. M. Hansen and two anonymous reviewers provided helpful comments that improved this manuscript.

\section{References}

Allan, J. D., D. L. Erickson, and J. Fay. 1997. The influence of catchment land use on stream integrity across multiple spatial scales. Freshwater Biology 37:149-161.

Allen, K. R. 1969. Limitations on production in salmonid populations in streams. Pages 3-18 in T. G. Northcote, editor. Symposium on salmon and trout management in streams. University of British Columbia, Vancouver.

Beauchamp, J. J., S. W. Christensen, and E. P. Smith. 1992. Selection of factors affecting the presence of brook trout (Salvelinus fontinalis) in Adirondack lakes: a case study. Canadian Journal of Fisheries and Aquatic Sciences 49:597-608.

Belsley, D. A., E. Kuh, and R. E. Welsch. 1980. Regression diagnostics: identifying influential data and source of collinearity. Wiley, New York.

Bryce, S. A., and S. E. Clarke. 1996. Landscape-level ecological regions: linking state-level ecoregion frameworks with stream habitat classifications. Environmental Management 20:297-311.

Cade, B. S., J. W. Terrell, and R. L. Schroeder. 1999. Estimating effects of limiting factors with regression quantiles. Ecology 80(1):311-323.

Carl, L. M. 1980. Aspects of the population ecology of Chinook salmon in Lake Michigan tributaries. Doctoral dissertation. University of Michigan, Ann Arbor.

Carnes, B. A., and N. A. Slade. 1988. The use of regression for detecting competition with multicollinear data. Ecology 69(4):1266-1274.

Chapman, D. W., and T. C. Brown. 1969. Distribution of salmonids in streams, with special reference to food and feeding. Pages 153-176 in T. G. Northcote, editor. Symposium on salmon and trout management in streams. University of British Columbia, Vancouver.

Connor, W. P., H. L. Burge, J. R. Yearsley, and T. C. Bjornn. 2003. Influence of flow and temperature on survival of wild subyearling fall Chinook salmon in the Snake River. North American Journal of Fisheries Management 23:362-375.

Curry, K. D., and A. Spacie. 1979. The importance of tributary streams to the reproduction of catastomids and sauger. Purdue University Water Resources Research Center, Technical Report 126, West Lafayette, Indiana.

Dunham, J. B., and G. L. Vinyard. 1997. Relationships between body mass, population density, and the self-thinning rule in stream-living salmonids. Canadian Journal of Fisheries and Aquatic Sciences 54:1025-1030.

Farrar, D. E., and R. R. Glauber. 1967. Multicollinearity in regression analysis: the problem revisited. Review of Economics and Statistics 49(1):92-107. 
Fausch, K. D., C. L. Hawkes, and M. G. Parsons. 1988. Models that predict standing crop of stream fish from habitat variables: 1950-1985. U.S. Forest Service, Pacific Northwest Research Station, General Technical Report PNW-GTR-213, Portland, Oregon.

Frissell, C. A., W. J. Liss, C. E. Warren, and M. D. Hurley. 1986. A hierarchical framework for stream habitat classification: viewing streams in a watershed context. Environmental Management 10:199214.

Galloway, J. E., and N. R. Kevern. 1976. Michigan suckers: their life histories, abundance, and potential for harvest. Michigan Sea Grant, Technical Report 53, East Lansing.

Gordan, D. J., and H. R. MacCrimmon. 1982. Juvenile salmonid production in a Lake Erie nursery stream. Journal of Fish Biology 21:455-473.

Graham, M. H. 2003. Confronting multicollinearity in ecological multiple regression. Ecology 84(11): 2809-2815.

Hinz, L. C., Jr., and M. J. Wiley. 1997. Growth and production of juvenile trout in Michigan streams: influence of temperature. Michigan Department of Natural Resources, Fisheries Research Report 2041, Ann Arbor.

Hughes, R. M., E. Rexstad, and C. E. Bond. 1987. The relationship of aquatic ecoregions, river basins, and physiographic provinces to the ichthyogeographic regions of Oregon. Copeia 1987(2):423-432.

Jackson, D. A., P. R. Pres-Neto, and J. D. Olden. 2001. What controls who is where in freshwater fish communities: the roles of biotic, abiotic, and spatial factors. Canadian Journal of Fisheries and Aquatic Sciences 58:157-170.

James, F. C., and C. E. McCulloch. 1990. Multivariate analysis in ecology and systematics: panacea or Pandora's box? Annual Review of Ecology and Systematics 21:129-166.

Larsen, D. P., J. M. Omernick, R. M. Hughes, C. M. Rohm, T. R. Whittier, A. J. Kinney, A. L. Gallant, and D. R. Dudley. 1986. Correspondence between spatial patterns in fish assemblages in Ohio streams and aquatic ecoregions. Environmental Management 10:815-828.

Levin, S. A. 1992. The problem of pattern and scale in ecology. Ecology 73:1943-1967.

Levins, R. 1966. The strategy of model building in population biology. American Scientist 54:421-431.

Lyons, J. 1996. Patterns in the species composition of fish assemblages among Wisconsin streams. Environmental Biology of Fishes 45:329-341.

Maxwell, J. R., C. J. Edwards, M. E. Jensen, S. J. Paustian, H. Parrott, and D. M. Hill. 1995. A hierarchical framework of aquatic ecological units in North America (nearctic zone). U.S. Forest Service, North Central Forest Experiment Station, General Technical Report NC-176, St. Paul, Minnesota.

Mitchell-Olds, T., and R. G. Shaw. 1987. Regression analysis of natural selection: statistical inference and biological interpretation. Evolution 41(6): 1149-1161.
Neter, J., M. Hunter, C. Nachtsheim, and W. Wasserman. 1996. Applied linear statistical models, 4th edition. WCB McGraw-Hill, Boston.

Pess, G. R., D. R. Montgomery, E. A. Steel, R. E. Bilby, B. E. Feist, and H. M. Greenberg. 2002. Landscape characteristics, land use, and coho salmon (Oncorhynchus kisutch) abundance, Snohomish River, Wash., U.S.A. Canadian Journal of Fisheries and Aquatic Sciences 59:613-623.

Pusey, B. J., M. J. Kennard, and A. H. Arthingon. 2000. Discharge variability and the development of predictive models relating stream fish assemblage structure to habitat in northeastern Australia. Ecology of Freshwater Fish 9:30-50.

Raleigh, R. F., T. Hickman, R. C. Solomon, and P. C. Nelson. 1984. Habitat suitability information: rainbow trout. U.S. Fish and Wildlife Service, Washington, D.C.

Raleigh, R. F., W. J. Miller, and P. C. Nelson. 1986. Habitat suitability index models and instream flow suitability curves: Chinook salmon. U.S. Fish and Wildlife Service, Washington, D.C.

Richards, C., and G. Host. 1994. Examining land use influences on stream habitats and macroinvertebrates: a GIS approach. Water Resources Bulletin 30:729-738.

Richards, C., L. B. Johnson, and G. E. Host. 1996. Landscape-scale influences on stream habitats and biota. Canadian Journal of Fisheries and Aquatic Sciences 53(Supplement 1):295-311.

Roth, N. E., J. D. Richards, and D. E. Erickson. 1996. Landscape influences on stream biotic integrity assessed at multiple spatial scales. Landscape Ecology 11:141-156.

Schlosser, I. J. 1995. Critical landscape attributes that influence fish population dynamics in headwater streams. Hydrobiologia 303:71-81.

Schlosser, I. J., and L. W. Kallemeyn. 2000. Spatial variation in fish assemblages across a beaver-influenced successional landscape. Ecology 81:1371-1382.

Scott, W. B., and E. J. Crossman. 1973. Freshwater fishes of Canada. Fisheries Research Board of Canada, Ottawa.

Seelbach, P. W. 1993. Population biology of steelhead in a stable-flow, low-gradient tributary of Lake Michigan. Transactions of the American Fisheries Society 122:179-198.

Seelbach, P. W., and M. J. Wiley. 1997. Overview of the Michigan rivers inventory (MRI) project. Michigan Department of Natural Resources, Fisheries Technical Report 97-3, Ann Arbor.

Sowa, S. P., and C. F. Rabeni. 1995. Regional evaluation of the relation of habitat to distribution and abundance of smallmouth bass and largemouth bass in Missouri streams. Transactions of the American Fisheries Society 124:240-251.

Stoneman, C. L., and M. L. Jones. 2000. The influence of habitat features on the biomass and distribution of three species of southern Ontario stream salmonids. Transactions of the American Fisheries Society 129:639-657.

Terrell, J. W., B. S. Cade, J. Carpenter, and J. M. Thomp- 
son. 1996. Modeling stream fish habitat limitation from wedge-shaped patterns of variation in standing stock. Transactions of the American Fisheries Society $125: 104-117$.

Thomson, J. D., G. Weiblen, B. A. Thomson, S. Alfaro, and P. Legendre. 1996. Untangling multiple factors in spatial distributions: lilies, gophers, and rocks. Ecology 77(6):1698-1715.

Trautman, M. B. 1981. The fishes of Ohio, revised edition. Ohio State University Press, Columbus.

USFWS (U.S. Fish and Wildlife Service). 1982. Atlas of the spawning and nursery areas of Great Lakes fishes, volume 8. Reproductive characteristics of Great Lakes fishes. USFWS, Ann Arbor, Michigan.

Walton, B. D. 1980. The reproductive biology, early life history, and growth of white suckers (Catastomus commersoni) and longnose suckers (C. catostomus) in the Willow Creek-Chain Lakes system, Alberta. Alberta Department of Energy and Natural Resources, Fisheries Research Report 23, Edmonton.

Wang, L., J. Lyons, P. Kanehl, and R. Bannerman. 2001. Impacts of urbanization on stream habitat and fish across multiple spatial scales. Environmental Management 28(2):255-266.

Wang, L., J. Lyons, and P. Kanehl. 2002. Effects of watershed best management practices on habitat and fish in Wisconsin streams. Journal of the American Water Resources Association 38(3):663-680.

Wang, L., J. Lyons, P. Rasmussen, P. Seelbach, T. Simon, M. Wiley, P. Kanehl, E. Baker, S. Miemela, and P. M. Stewart. 2003. Watershed, reach, and riparian influences on stream fish assemblages in the Northern Lakes and Forest Ecoregion, U.S.A. Canadian Journal of Fisheries and Aquatic Sciences 60:491505.

Wehrly, K. M., M. J. Wiley, and P. W. Seelbach. 1998. Landscape-based models that predict July thermal characteristics of lower Michigan rivers. Michigan Department of Natural Resources, Fisheries Research Report 2037, Ann Arbor.

Wehrly, K., M. J. Wiley, and P. W. Seelbach. 2003. Classifying regional variation in thermal regime based on stream fish community patterns. Transactions of the American Fisheries Society 132:18-38.

Wiley, M. J., S. L. Kohler, and P. W. Seelbach. 1997. Reconciling landscape and local views of aquatic communities: lessons from Michigan trout streams. Freshwater Biology 37:133-148.

Zorn, T. G., P. W. Seelbach, and M. J. Wiley. 2002. Distributions of stream fishes and their relationship to stream size and hydrology in Michigan's Lower Peninsula. Transactions of the American Fisheries Society 131:70-85.

Zorn, T. G. 2003. Fishes of lower Michigan rivers: distribution patterns, abundance models, and causal relationships. Doctoral dissertation. University of Michigan, Ann Arbor.

Zorn, T. G., P. W. Seelbach, and M. J. Wiley. 2004. Utility of species-specific, multiple linear regression models for prediction of fish assemblages in rivers of Michigan's Lower Peninsula. Michigan Department of Natural Resources, Fisheries Research Report 2072, Ann Arbor. 